\title{
TOXIC POLYNEURITIS ARISING DURING THE MANUFACTURE OF TRICRESYL PHOSPHATE
}

BY

\author{
DONALD HUNTER, KENNETH M. A. PERRY, AND R. BYRON EVANS
}

From the Department for Research in Industrial Medicine (Medical Research Council), The London Hospital

This communication records the toxic effects çaused by tri-ortho-cresyl phosphate in three men employed in its manufacture. Tricresyl phosphate is used in the recovery of phenol residues from gas plant effluents and also as a plasticizer in the plastics industry. A plasticizer is a substance used to render a plastic material more pliable, and by alteration of the amount of the plasticizer added, such characteristics as flexibility, hardness, water resistance and inflammability can be varied between wide limits. In this industry it is being used in increasing quantities, for example, as much as 50 per cent. of tricresyl phosphate is sometimes added to polyvinyl chloride. Tricresyl phosphate used in industry is an oil with a slightly pungent odour: of the three isomerides the ortho- and meta- are liquids, and the para- is a crystalline solid. Industrial tricresyl phosphate is prepared by treating cresols with phosphorus oxychloride in the presence of an aluminium catalyst. It has been the boast of industry in the United States of America that in a plant manufacturing $100,000 \mathrm{lb}$. of this material a day without any special precautions no cases of poisoning have occurred. However, since 1939 black-out regulations in Great Britain, imposed as a precaution against air attack, have led to a less fortunate state of affairs, and three workmen employed in a manufacturing plant have developed polyneuritis. As a result of these cases poisoning by tricresyl and triphenyl phosphate resulting from the manufacture or use of these products in industry was scheduled under the Workmen's Compensation (Industrial Diseases) Order, 1942, No. 1326.

\section{Environmental Conditions}

All three of these men worked in a room about 25 feet long, 12 feet wide, and 12 feet high which, owing to black-out regulations, was totally enclosed during the hours of darkness, although it was provided with a roof vent. During daylight doors and windows were open. The men worked at wash tanks which were roughly cubic vessels of about 5 feet high, with a partially open top. The closed-in portion of the top supported the various fittings, one of these being a 6 inch vent pipe extending through the roof to the open air. Crude tricresyl phosphate entered these tanks at a temperature of approximately $60^{\circ} \mathrm{C}$. At this stage it contained hydrochloric acid which gave it an unpleasant irritating odour. However, it was immediately cooled by treatment with an equal volume of cold water, this operation being carried out by opening a valve and shutting it at the appropriate moment. The washing was automatic, but

it was nevertheless possible for the men to inhale vapour from the tanks. The cold tricresyl phosphate is of low volatility, having a low vapour pressure at ordinary temperature. The ortho-isomer content of the finished product was about 60 per cent. The three affected men also handled triphenyl phosphate.

It was not possible at the time the men were poisoned to determine the concentration of tricresyl phosphate which was present in the atmosphere. This, however, was estimated at a later date when conditions were arranged to reproduce those in operation at the time. The injectors, fans and air conditioning plant were shut off, the covers of the washing vats left open, and the water drained from the cooler. The determinations were carried out during daytime, and also during simulated and actual black-out conditions. The highest concentration of tricresyl phosphate was found in the room containing the washing vats after the hot liquid had been blown over from the reaction vessels into the washing vats. Twenty litres of atmosphere were aspirated through an absorption train for 16 to 30 minutes, commencing $5-10$ minutes before the end of the delivery of hot liquid. The absorption train consisted of 2 bubblers, each containing $100 \mathrm{mls}$. of alcohol, followed by 2 tubes packed with glass wool and cotton wool respectively. Over 90 per cent. of the tricresyl phosphate was found in the first bubbler, the remainder in the second, and none in the wools. The tricresyl phosphate was determined by estimating colorimetrically the $\mathbf{P}_{2} \mathbf{O}_{5}$ produced by its decomposition.

TABLE 1

SAMPLES OF ATMOSPHERE FROM A POINT INSIDE THE WASHING VAT 6-9 INCHES ABOVE THE FINAL LEVEL OF THE LIQUID.

Tricresyl phosphate

Mgs, per 20 litres

Mgs, per culim.

Marts per millio

Parts per million vol/vol.

A
$0 \cdot 2$
10
8
0.6

Daytime

B
$0 \cdot 2$
10
8
$0 \cdot 6$

TABLE 2

SAMPLES OF ATMOSPHERE FROM A POINT 9 INCHES ABOVE THE TOP OF THE WASHING VAT AND OVER THE CENTRE OF THE

\section{OPENING.}

Tricresyl phosphate

Mgs. per 20 litres

Mgs. per cu.m.

Parts per million wt/wt.

Parts per million vol/vol. 
TABLE 3

SAMPLES OF ATMOSPHERE FROM A POINT AT SHOULDER HEIGHT FROM THE FLOOR AND 2 FEET IN FRONT OF THE WASHING VAT.

\begin{tabular}{|c|c|c|}
\hline Tricresyl Phosphate & $\begin{array}{l}\text { Simulated } \\
\text { black-out }\end{array}$ & $\begin{array}{c}\text { Actual } \\
\text { black-out }\end{array}$ \\
\hline Mgs. per 20 litres & $<0.02$ & $<0.02$ \\
\hline Mgs. per cu.m. & $<1 \cdot 0$ & $<1.0$ \\
\hline Parts per million wt $/$ wt. .. & $<1.0$ & $<1 \cdot 0$ \\
\hline Parts per million vol/vol. & $<0.06$ & $<0.06$ \\
\hline
\end{tabular}

Finally, samples of the atmosphere in one of the rooms containing washing vats were taken over a period of 24 hours on three occasions. In these experiments the alcohol in the bubblers was replaced by $20 \mathrm{mls}$. of ethylene glycol monomethyl ether in the first and $25 \mathrm{mls}$. of water in the second. These samples were drawn from a point 4 feet 9 inches above the lower step, 3 inches in front of the washer and 3 inches along the opening from the right-hand end. Black-out conditions were in operation during black-out times in the month of April.

TABLE 4

$$
\text { A B C }
$$

Volume of atmosphere

tested $\ldots \quad \ldots \quad \ldots 16 \mathrm{cu} . \mathrm{ft} .30 \mathrm{cu} . \mathrm{ft} .26 \mathrm{cu} . \mathrm{ft}$.

Tricresyl phosphate

Mgs. in volume under test

Mgs. per cu.m. .

Parts per million vol/vol.

0.75
1.66
1.28

$0 \cdot 10$
0.47

0.55

0.42

0.03

0.67

0.91

$0 \cdot 70$

0.06
The method of estimating the tricresyl phosphate was as follows:-1 ml. of a dilute solution of tricresyl phosphate $(0.1 \mathrm{mg}$.) in alcohol was transferred to a platinum dish with $25 \mathrm{mls}$. of alcohol and $2 \mathrm{mls}$. of N/10 KOH solution. The dish was placed on a water bath and heated until dry. The dish was then gently heated, using a low flame until charring finished, and then more strongly to remove the bulk of the carbon. The dish and contents were allowed to cool and $5 \mathrm{mls}$. of water and 2 drops of nitric acid were added and mixed. At this stage the solution was definitely acid. The dish was transferred to a water bath and the solution evaporated to dryness. The residue was dissolved in a little water and transferred to a test tube $(6$ in. $\times 1$ in.) $1 \mathrm{ml}$. of 0.01 per cent. $\mathrm{Na}_{2} \mathrm{HPO}_{4} 12 \mathrm{H}_{2} \mathrm{O}\left(\mathrm{P}_{2} \mathrm{O}_{5} \equiv 0.1 \mathrm{mg}\right.$. tricresyl phosphate), $2 \mathrm{mls}$. of $\mathrm{N} / 10 \mathrm{KOH}$ and 2 drops of nitric acid were placed in a control tube. The level of liquids in both tubes were adjusted to the same height and to both tubes were added, with shaking, $0.5 \mathrm{mls}$. of molybdate reagent $(5 \mathrm{gms}$. of ammonium molybdate dissolved in $100 \mathrm{mls}$. of cold water and poured into $35 \mathrm{mls}$. of nitric acid $(\mathrm{d}=1.2)$ ) followed by $0.5 \mathrm{mls}$. of benzidine reagent $(0.05$ gms. of benzidine hydrochloride dissolved in $10 \mathrm{mls}$. of glacial acetic acid and diluted with water to $100 \mathrm{mls}$.). Ammonia was then added to both tubes approximately simultaneously to develop alkalinity and the blue colour. Both solutions gave colours of the same intensity and the results can be regarded as quantitative.

It is important that contact with any glass, including stirring rods, be avoided when the solutions are hot and alkaline as traces of silica are absorbed and nullify the results.

\section{Case Histories}

Case 1. E.R., a man aged 41 years. For three years before admission to hospital the patient had been employed in a chemical factory, at first working on nitrating processes. Six months later he began to handle cresol, phenol, phosphorous oxychloride, caustic soda and sulphuric acid making tri-ortho-cresyl phosphate and triphenyl phosphate. For six months before admis- sion the process was speeded up for Government contract and the plant production rose by 30 per cent. He worked every Sunday instead of one in four. Two weeks before he was seen he complained of slight stiffness of the neck. For two days before he had had lower abdominal pain accompanied by diarrhoea, passing three pale watery stools per day. Five days later he suddenly found he could not walk properly. He was unable to lift his toes and his feet dragged. The disability progressed until eventually he was unable to stand without the help of a stick. He then found that he had weakness of the fingers of both hands and he was unable to do up buttons. There were occasional tingling sensations and numbness in the calves of both legs. Previous history.-Bronchitis during the last year. Family history.-Father and mother dead. Three brothers and two sisters alive and well. There was no familial nervous disease. Condition on admission.-Robust man. Afebrile. No abnormality in respiratory, cardiovascular or gastrointestinal systems. Nervous system: no mental abnormality; no abnormality detected in cranial nerves; fundi normal. Upper limbs: weakness of hand grip and of dorsi-flexion of both wrists: slight symmetrical wasting of thenar, hypothenar and first dorsal interosseous muscles. Reflexes all present and equal. No sensory loss. Lower limbs: great weakness of dorsiflexors and plantar flexors of ankles; slight symmetrical wasting of calves; flail ankle joints; knee jerks brisk and equal; ankle jerks absent; plantar responses flexor. Slow, high-stepping, rather stamping gait. Two-point discrimination normal; appreciation of pin-prick, cotton wool touch, vibration and posture normal. Special examinations.-Blood count: Haemoglobin (Sahli) 92 per cent., white cells 8200 per $\mathrm{cmm}$., differential count normal; no abnormality seen in stained film. Blood Wassermann reaction negative. Lumbar puncture: pressure $95 \mathrm{~mm}$. of cerebro-spinal fluid; Queckenstedt's test normal; fluid clear and colourless; no excess of white cells; protein $18 \mathrm{mg}$. per $100 \mathrm{cc}$., Wassermann reaction negative. Fractional test meal: no free hydrochloric acid for $2 \frac{1}{2}$ hours, later rose to 0.08 per cent. Urine: no albumin or sugar. Progress.-He was treated with vitamin $\mathrm{E}$ by mouth and vitamin $\mathrm{B}$ intra-muscularly. His muscles were treated first by rest and then with massage and galvanism. After the third week he began to show slow but steady improvement and six months after admission he was discharged. He then walked with a high-steppage gait. Uplifting toe springs fitted to his boots helped him. One year after admission he had completely recovered and was able to return to work.

Case 2. G.M., a man aged 30 years (L.H. Reg. No. M.168/1941). For 8 months previous to admission the patient had been employed in the manufacture of tricresyl phosphate and was in contact with the same substances as case 1 . He worked for 63 hours per week. Five months later he began to complain of cramp-like pains in the thighs, calf muscles and toes. About the same time he noticed that he had recurrent attacks of hiccup. One month before admission he had an attack of diarrhoea, unaccompanied by abdominal pain or vomiting, which lasted one day, and soon afterwards he noticed that his feet were weak and found that he had to lift up his legs to prevent his toes dragging along the ground. He found that he could only walk with difficulty and consequently took to bicycling. More recently he complained of 'fluttering' of various muscles all over his body, chiefly forearms, neck and thighs. Previous history.-He had scarlet fever with acute nephritis as a child. At the age of 15 he was employed in the production of lead arsenate and had several attacks of abdominal colic. Five years before admission he developed a secondary anaemia which responded well to iron. Family history. - Father died of pneumonia at the age of 50. Mother and one brother and four sisters alive and well. There was no familial nervous disease. Condition on admission. - Intelligent, slightly pale man. Weight 10 st. 5 lb. Afebrile. Yellow stain on hands 
and particularly around finger nails. Caustic soda ulcer on one finger. Cold, moist hands and feet. No abnormality discovered in the respiratory, cardiovascular or gastro-intestinal systems. Nervous system: no mental abnormality; concomitant strabismus; congenital nystagmus; fundi and pupils normal. Upper limbs: weakness of flexors and extensors of wrists and fingers, of dorsal and palmar interossei and lumbricals; wasting of thenar and hypothenar eminences and of first dorsal interosseous muscle, some hypotonus of muscles of the wrists; reflexes all present and equal; no sensory loss. Abdominal reflexes present and equal. Lower limbs: gross weakness of dorsi-flexors and plantar flexors of both feet; he was unable to move his toes; wasting and hypotonus of both calves, the left is half an inch smaller than the right; wasting and hypotonus of tibialis anticus on both sides; flail ankle joints; sensation unimpaired; calves and tendo-Achilles very tender on pressure; fibrillation of muscles of thighs and forearms; knee jerks exaggerated; ankle jerks absent; plantar responses flexor. Slow, high-stepping gait with dragging of feet. Special examinations.-Blood count: red cells $4,500,000$ per $\mathrm{cmm}$., haemoglobin (Sahli) 88 per cent., colour index $0 \cdot 9$, white cells 13,400 per $\mathrm{cmm}$., differential count normal; no abnormality seen in stained films. Blood Wassermann reaction negative. Lumbar puncture: pressure $100 \mathrm{~mm}$. of cerebro-spinal fluid; Queckenstedt's test normal; ;fluid clear and colourless; no excess of white cells; protein $20 \mathrm{mg}$. per $100 \mathrm{cc}$., Wassermann reaction negative. Urine: no albumin or sugar. Progress.-For six weeks after admission the weakness of the feet became worse. After three months, however, there were signs of improvement, the patient being able to move some of his toes. The flexors and extensors of the wrists were improved. Fibrillary tremors of thighs were particularly marked. Plantar responses unobtainable. He was treated with vitamin $\mathbf{B}_{1}$ intra muscularly and with massage and movements. He continued to make progress and regained power in the upper limbs which returned to normal. There was great improvement in dorsi-flexion and plantar flexion of the foot, and he was discharged from hospital after 19 months, wearing uplifting toe springs. He continued to make slow progress and after $3 \frac{1}{2}$ years there were only slight residual signs, and he returned to work.

Case 3. G.S., a man aged 38 years. (L.H. Reg. No. M.252/1941). For six months before admission the patient had been employed in the manufacture of triortho-cresyl phosphate, and he did exactly the same job as the other two men. During this time he had complained of cramp-like pains in the hands which came on after he had been lifting heavy drums. Ten days before admission he had diarrhoea, passing 5 stools per day for 2 days unaccompanied by abdominal pain, and 1 day later he noticed that his toes dragged along the ground and that his feet slapped down as he walked. At the same time there was a severe aching pain in his calf muscles, particularly on standing or walking, and at intervals severe stabbing, shooting pains in the same group of muscles. He also had severe pains in his hands radiating upwards into the forearms and he found he was unable to extend his fingers which became fixed in a position of semi-flexion. As this pain gradually wore off so also was he able to straighten his fingers. The weakness of his legs gradually became worse. Previous history.-At the age of 33 he was admitted to hospital with a history of having drunk spirits of salts. Family history.-Wife died by suicide. Three children alive and well. Two brothers and one sister alive and well. There was no familial nervous disease. Condition on admission.-Well nourished man. Afebrile. Quantities of yellow material around nail beds. No abnormality in cardiovascular, respiratory or gastrointestinal systems. Harrison's sulcus. Scoliosis. Nervous system: no mental abnormality; no abnormality in cranial nerves ; fundi normal. Upper limbs: slight weakness of extension of wrists, especially left ; no wasting or alteration in tone; reflexes all present and equal; no sensory loss. Abdominal reflexes present and equal Lower limbs: weakness of dorsi-flexors and less of plantar flexors of feet; slight wasting of calf muscles, more of tibialis anticus; general slight flaccidity of plantar and dorsi-flexors of feet; fibrillary tremors of thigh muscles; no impairment of sensation; marked tenderness of calves and tendo-Achilles; knee jerks present and equal; absent ankle jerks; plantar responses flexor. Gait slow and high-stepping. Special examinations.-Blood count : red cells $4,700,000$ per c.mm., haemoglobin (Sahli) 92 per cent., colour index $0 \cdot 9$, white cells 8000 per c.mm., differential count normal; no abnormality seen in stained films. Blood Wassermann reaction negative. Lumbar puncture: pressure $100 \mathrm{~mm}$. of cerebro-spinal fluid; Queckenstedt's test normal; fluid clear and colourless; no excess of white cells; protein $100 \mathrm{mg}$. per $100 \mathrm{cc}$; Wassermann reaction negative. Urine: no albumin or sugar. Progress.- He was treated with vitamin $\mathbf{B}_{\mathbf{1}}$ intramuscularly and with massage and movements. He made steady progress and the power in the legs returned with increased ability to dorsi-flex his feet. Movement returned in both big toes after four months, but fibrillary tremors of thigh muscles persisted. He was discharged after ten months in hospital, able to walk with no evidence of foot-drop, and he returned to work.

The clinical picture of tri-ortho-cresyl phosphate poisoning is that of a polyneuritis with flaccid paralysis of the distal muscles of the upper and lower extremities. Slow but complete recovery usually occurs. These three cases were of men engaged in the manufacture of tricresyl phosphate. Up to the present time no case has been reported in men using the substance as a plasticiser or in those moulding plastics. As is shown later, however, plastic materials containing tricresyl phosphate have given rise to symptoms in experimental animals.

Opportunities to study this clinical picture occurred during a period of 40 years prior to the discovery of the first victim of industrial poisoning. It was encountered in patients treated for pulmonary tuberculosis with phospho-creosote, in people who had partaken of an alcoholic beverage known as Jamaica ginger or jake, in women who had taken apiol as an abortifacient, and in certain victims fed on a soya bean cooking oil adulterated by accident.

\section{Previous Outbreaks of Poisoning with Tricresyl Phosphate}

In 1899 Lorot reported six cases of multiple neuritis out of 41 cases of pulmonary tuberculosis treated with phospho-creosote. This substance was discovered in 1894. Later it was shown to contain 15 per cent. of tri-ortho-cresyl phosphate. In the next 35 years 53 additional cases were recorded in various parts of Continental Europe (Roger and Recordier, 1934).

In the spring of 1930 there appeared suddenly, in the mid-western and south-western states of the United States of America, an outbreak of paralysis characterized by bilateral foot- and wrist-drop. During March and April of that year almost 4,000 cases were reported in the press throughout the United States of America. During the whole year 15,000 people were affected, and of these 10 died. A connexion was immediately recognized between this paralysis and the ingestion of adulterated samples of the popular alcoholic drink already mentioned-Jamaica ginger or jake. The quantity of ginger fluid consumed was not the determining factor in the severity of the symptoms which followed; a single drink is known to have produced 
the same result as that following the use of the beverage for many days.

The clinical picture develops by three stages. In some cases there are early transient gastro-intestinal symptoms including nausea, vomiting, diarrhoea, and abdominal pain. These clear up and a symptom-free interval follows lasting from 5 to 21 days, the average being 10 days. This interval is followed by soreness of the muscles below the knees and numbness of the toes and fingers lasting several days and followed by weakness of the toes and bilateral foot-drop. After another interval of about 10 days weakness of the fingers and wrist-drop follows. This paralysis is not usually as severe as that in the feet and legs. In the upper extremities paralysis does not extend above the elbows. The thigh muscles may be involved in advanced cases. There are neither sensory changes nor loss of sphincter control.

By July, 1930, Smith and Elvove proved that the adulterated beverage contained about two per cent. of tri-ortho-cresyl phosphate and that this caused the paralysis. The reason for including this substance as one of the ingredients will probably never be known. It may have been used on account of its physical properties. By subcutaneous injection of samples of the adulterated drink, as well as of pure synthetic tri-ortho-cresyl phosphate, Smith and Elvove succeeded in producing a paralysis comparable to that seen in human beings in a variety of laboratory animals including hens, rabbits, calves, dogs and monkeys.

Zeligs (1938) had the opportunity to follow up 316 cases of jake paralysis during 6 years. His description of the clinical picture in 1930 and later in 1936 shows that the poison may attack the anterior horn cells and the pyramidal tracts, in addition to the peripheral motor nerves. In 1930 all the patients had typical foot-drop, the degree of paralysis varying from slight muscular weakness to complete flaccid paralysis of all the muscles of the feet and legs. In about three-fourths of the cases the upper extremities became similarly involved, wrist-drop being common. The ankle jerks were absent, the knee jerks present and in many cases over-active. There were no abnormal plantar responses and no ankle clonus. Sensory changes were absent. During the next six years many of the patients recovered completely and others improved sufficiently to be able to use their hands and feet adequately. Out of 316 patients admitted to the Cincinnati General Hospital in 1930 a group of 60 were found still in institutions in 1936. They hobbled about with the aid of sticks. Physical examination showed spastic paralysis with adductor spasm, paralytic talipes, exaggerated tendon reflexes, and extensor plantar responses. In the upper extremities there was marked atrophy of the extensors of the wrists and of the interossei, with bilateral claw hands.

The initial conception of tri-ortho-cresyl phosphate poisoning as being a peripheral neuritis is therefore no longer tenable. The anterior horn cells and pyramidal tracts may sometimes be affected too, but the extreme muscular wasting tends to mask the involvement of the upper motor neurone. When muscular activity is partially restored the spastic signs of the previously hidden upper motor neurone lesion become clinically apparent. In such cases the end result resembles amyotrophic lateral sclerosis.
In 1931 ter Braak reported in Holland an outbreak of some 40 cases of paralysis from the use of apiol as an abortifacient. During 1931 and 193250 more cases were published from Germany, France, Switzerland, and Jugoslavia. Samples of apiol were found to be adulterated with tri-ortho-cresyl phosphate to the extent of 28 to 50 per cent. (Germon, 1932). Nobody knows why this substance was chosen as an adulterant. Neither in colour, taste, nor odour do the two oils resemble each other. In the women affected there was a lower motor neurone paralysis of the distal muscles of the extremities, without sensory loss.

In April, 1937, there occurred an outbreak affecting 68 people who had partaken of soya bean oil used for salads and for cooking. Forty-one of these people lived in Natal and the other 27 travelled in a ship which had been provisioned in Durban (Sampson, 1938, 1942). This oil was found to contain 0.4 per cent. of tri-ortho-cresyl phosphate. The victims first had gastro-intestinal symptoms and 7 to 14 days later developed cramps in the calves of their legs. Ultimately lower motor neurone paralysis of the feet and hands supervened, but sensation was unimpaired.

Cases of tri-ortho-cresyl phosphate poisoning have recently occurred in Münster owing to shortage of fats in Germany. The patients were factory workers who had obtained a fat substitute from their place of work. They had taken it home and, because of the shortage of natural animal and vegetable fats, had used it to fry potato pancakes. They developed nausea, vomiting, abdominal cramps, and diarrhoea, followed in 10 days by rapidly increasing weakness of the feet, legs, and then arms. There was progressive atrophy of the muscles. As a result of this outbreak, a warning was issued to factory medical officers in Germany, who were instructed to prevent recurrences by education and propaganda (Humpe, 1942).

\section{Portal of Entry}

Hamilton (1934) suggested that dangerous exposure to tri-ortho-cresyl phosphate might occur in the mixing of lacquers containing this material as a plasticizer, particularly if the ingredients were heated.

Hodge and Sterner (1943) estimated the amount of tri-ortho-creśyl phosphate that can be absorbed through unbroken skin, and how rapidly the absorption occurs. Tri-ortho-cresyl phosphate containing radio-active phosphorus was used and the absorption measured in two human subjects and one dog. The human subjects applied $0.22 \mathrm{~g}$. and $0.11 \mathrm{~g}$. of the tri-ortho-cresyl phosphate with radio-activity of 395,000 counts $/ \mathrm{mm} . / 0 \cdot 1 \mathrm{~g}$. The first had thirteen micrograms of tri-ortho-cresyl phosphate per $100 \mathrm{cc}$. of blood at the end of one hour, and he excreted seven micrograms in the urine in the first hour, and continued at 35 micrograms an hour for the next 24 hours. He excreted 797 micrograms or 0.36 per cent. of the amount applied. The second had four micrograms per $100 \mathrm{cc}$. of blood at the end of one hour, and excreted 143 micrograms or 0.13 per cent. of the amount applied.

$2.094 \mathrm{~g}$. of the tri-ortho-cresyl phosphate was applied to the abdomen of a bitch and the blood level quickly established itself at 8 micrograms/ $100 \mathrm{cc}$., and maintained this for 24 hours. The urinary excretion began equally promptly, being 
44 micrograms in the first hour, rising after seven hours to a maximum of 1312 micrograms. The radio-active phosphate was distributed in the various tissues of the dog 24 hours after its application to the abdominal surface. Retention was in the following order:-visceral organs, muscle, brain, bone.

The authors consider that the magnitude of absorption of tri-ortho-cresyl phosphate through human skin is such that a real hazard exists in industrial operations permitting a considerable or repeated exposure to this compound. A safe industrial hygiene control requires that measures be taken to prevent such skin contact, and that all workmen exposed to the compound be instructed as to the hazard, and the necessity for preventing skin contamination.

Because of the low volatility of tri-ortho-cresyl phosphate and the low vapour pressure at ordinary temperature, it has been argued that poisoning cannot occur from inhalation. However, the fact that in our cases the symptoms were precipitated by the introduction of black-out conditions suggested that poisoning may arise in this way. Further, in order to try to prevent recurrence, the firm employing the men fitted the wash tank room with ventilators and a fan. The tanks were closed in and the vents fitted with injectors, so that the vapours might be quickly transferred to the open air. Since these precautions no further cases of poisoning have occurred, and it is therefore possible that the lungs were the portal of entry of the poison in our cases. However, the black-out conditions in the plant raised the temperature: and the introduction of a more elaborate ventilating system substantially lowered this temperature. In view of the atmosphere concentrations a more probable explanation is that increased sweating caused greater absorption through the skin.

\section{Experimental Evidence of Toxicity}

Smith and Elvove (1930) showed that the specific toxicity of tri-ortho-cresyl phosphate for the motor nerves is not shared by the meta or para cresyl esters or by the phenyl ester. The dosage of tri-ortho cresyl phosphate was approximately 30 times less than that of triphenyl phosphate. Flinn (1943) was able to produce paralysis in 28 days in domestic fowls fed with cellophane, containing 11 per cent. of tri-ortho-cresyl phosphate, in amounts of $1 \mathrm{gm}$. per kilo of body weight.

Attempts were made to confirm these experimental observations. Twelve twelve-week old hens were obtained and fed with gelatin coated capsules containing $0.5 \mathrm{~g}$. of one of the pure isomers of tricresyl phosphate or triphenyl phosphate. Four hens were used as controls, and two each were fed with tri-meta, tri-para, and tri-ortho-cresyl phosphate and triphenyl phosphate. Unfortunately two of the controls developed fowl paralysis after the others had had $2 \mathrm{~g}$. of the drug. It was noticed, however, that the two hens which received the tri-ortho-cresyl phosphate became completely paralysed in the wings and legs. The fowl paralysis in the controls rendered this experiment unsatisfactory, and it was therefore repeated with 12 twelve-week old cockerels. After receiving $3 \mathrm{~g}$. of tri-ortho-cresyl phosphate two cockerels became paralysed and died four days after receiving $3.5 \mathrm{~g}$. After $12.5 \mathrm{~g}$. the two cockerels fed with tri-meta-cresyl phosphate showed con- siderable weakness of the legs, and after $15 \cdot 5 \mathrm{~g}$. they developed respiratory paralysis. They were grossly emaciated and were then killed. The cockerels which were fed with tri-para-cresyl phosphate and triphenyl phosphate showed no evidence of illhealth after they had received $25 \mathrm{~g}$.

\section{Measures for Prevention of Poisoning}

Since there is experimental evidence that triortho-cresyl phosphate can be absorbed through the skin, it is important, as a measure of prevention, that workers with these compounds should wear elbow length gloves to protect their hands and arms, and should change into special clothing during their working hours. This will prevent the possibility of smoking and food being eaten and thus contaminated with dirty hands. Bathing facilities for use at the end of the work period are also desirable. In the cases described in this paper the portal of entry may have been the respiratory tract, and therefore all rooms where the substances are used should be provided with exhaust ventilation. Tanks should be closed in and the vents fitted with ejectors so that the vapours may be quickly transferred to the open air.

\section{Summary}

The literature of the toxicity of tricresyl and triphenyl phosphate is reviewed. An account is given of the cases of three men who developed a toxic polyneuritis while working in industry in the manufacture of tricresyl phosphate. Experiments on domestic fowls confirm that tri-ortho-cresyl phosphate is toxic. $3.5 \mathrm{~g}$. of tri-ortho-cresyl phosphate killed two twelve-week old cockerels. $12 \cdot 5 \mathrm{~g}$. of tri-meta-cresyl phosphate produced weakness of the legs, and $15 \cdot 5 \mathrm{~g}$. respiratory paralysis, whereas $25 \mathrm{~g}$. of tri-para-cresyl phosphate and triphenyl phosphate produced no effect. Measures for the prevention of poisoning are discussed.

We are much indebted to Mr. R. Milton and Dr. J. Graham for help with the animal experiments, and to the research chemists of Messrs. A. Boake, Roberts \& Co., Ltd., for preparing the isomers of tricresyl phosphate in pure form for these experiments.

\section{REFERENCES}

ter Braak, J. W. G. (1931). Nederl. Tijdschr. Geneesk, 75, 2329.

Flinn, F. B. (1943). Personal communication.

Germon, G. (1932). Intoxication Mortelle par l'Apiol. Thèse de Paris.

Hamilton, A. (1934). Industrial Toxicology, New York, Harper and Brothers; p. 195.

Hodge, H. C. and Sterner, J. H. (1943). J. Pharm. exper. Ther., 79, 225.

Humpe, F. (1942).' Münch med. Wschr., 89, 448.

Lorot, C. (1899). Les combinaisons de la crésote dans le traitement de la tuberculose pulmonaire. Thèse de Paris.

Roger, H., and Recordier, M. (1934). Ann. de Méd., 35,44 .

Sampson, B. F. (1938). Bull. Off. int. Hyg. publ., 30, 2601.

(1942). S. Afr. med. J., 16, 1.

Smith, M. I., Elvove, E., et al. (1930). Publ. Hith. Rept., Wash., 45, 1703, 2509.

Zeligs, M. A. (1938). J. nerv. ment. Dis., 87, 464. 